2016 - Volume: 17 Number: 2

Page: 279 - 286

DOI : $10.18038 /$ btda. 48930

Received: 29 February 2016

Revised: 13 May 2016 Accepted: 16 May 2016

\title{
EXPERIMENTAL INVESTIGATION OF THE APPROACH ANGLE EFFECTS ON THE DISCHARGE EFFICIENCY FOR BROAD CRESTED WEIRS
}

\author{
Ayşegül ÖZGENÇ AKSOY ${ }^{1, *}$, Mustafa DOĞAN ${ }^{1}$ \\ ${ }^{1}$ Civil Engineering Department, Dokuz Eylul University, İzmir, TURKEY
}

\begin{abstract}
In open channels broad crested weirs are widely used to measure the discharge values. In this study the effect of the approach angle on the discharge efficiency of the broad crested weir was investigated experimentally. Four different approach angles were tested under steady state conditions by using three different discharge values. Experimental results indicate that the discharge coefficient is not only a function of crest length but also a function of approach angle. A modified new non dimensional empirical relation involved approach angle has been proposed.
\end{abstract}

Keywords: Broad crested weirs, Discharge coefficient, Approach angle

\section{INTRODUCTION}

The measurement of discharge at gauging stations in open channels such as rivers is important. Broad crested weirs are commonly used to measure the discharge and flow controls in open channels. Broad crested weir are mostly flat horizontal blocks but those have gradually raised upstream faces pass better sediment and debris. The discharge efficiency has been the subject of much research.

Hager and Schwalt [1] were analyzed experimentally the flow features over the broad-crested weir with vertical upstream wall and sharp-crested corner and proposed the discharge-head relation for submerged flow under a novel approach. Fritzi and Hager [2] determined the discharge coefficient in terms of relative crest length for long broad-crested, broad-crested, short-crested, and thin-crested weirs with a side slope $1 \mathrm{~V}: 2 \mathrm{H}$. Farhoudi and Alami [3] performed experiments to investigate the effect of upstream slope of rectangular broad crested weirs on discharge efficiency. They indicated that the weir discharge efficiency is reaching to its maximum at slope angle of $25^{\circ}$. Gogus et al. [4] investigated the effects of width of the lower weir crest and step height of broad-crested weirs of rectangular compound cross section on the values of the discharge coefficient, the approach velocity coefficient, and the modular limit experimentally. They provided extensive data outlining the performance of broad-crested weirs with compound cross section and different step heights. In the study of Sargison and Percy [5] the flow over a trapezoidal broad-crested weir with varying upstream and downstream slopes was analyzed. They indicated that the effect of the downstream slope is negligible on the variation of the water surface profile. Goodarzi et al. [6] investigated the hydraulic characteristics of flow over sloped-face broad-crested weirs. A new correction factor to estimate discharge coefficient for sloped-face broad-crested weirs was presented. The study of Parilkova et al. [7] belongs to the effect of surface roughness on the variation of discharge coefficient for broadcrested weirs. As a result of this study, a method for determination of the head-discharge relation for broad-crested weirs with a rough crest surface is proposed. Jalil et al. [8] realized a study to investigate the effect of the surface roughness on the discharge coefficient for broad-crested weirs. Experimental results of this study indicate that the performance of the broad-crested weirs improve with decreasing the relative roughness height and with increasing the relative total head. In Zachoval et al. [9] study, calculation of the discharge coefficient for rectangular sharp-edged broad-crested weir was

*Corresponding Author: aysegul.ozgenc@deu.edu.tr 
experimentally analyzed. The effects of friction and surface tension on the variation of discharge coefficient were taken into account. In the study of Madadi et al. [10] the effect of upstream face slope of a trapezoidal broad-crested weir on discharge was experimentally investigated. In consequence of the experiments it was found out that decreasing the upstream face slope avoid development of separation zone. Badr and Mowla [11] performed an experimental study to investigate the effect of sloped upstream side of broad-crested weirs over the discharge coefficient and flow characteristics. They indicated that decreasing the slope of the upstream side cause increasing the discharge efficiency and the discharge capacity of the weir.

In present study a series of experiments were performed to investigate the discharge efficiency of the broad crested weir. Experiments were conducted in a rectangular flume under steady state flow conditions.

The free flow and the notations are shown in Figure 1. In this figure $\mathrm{h}_{0}$ is the approach overflow depth, $H_{0}$ is the approach overflow energy head, $w$ is the weir height, $L_{w}$ is the weir crest length and $\theta$ is the approach angle.

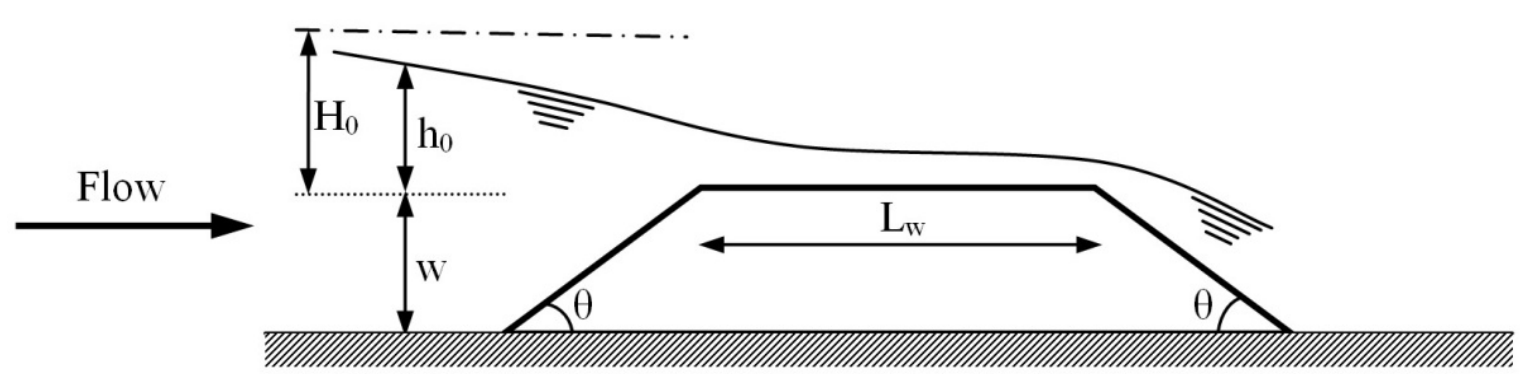

Figure 1. The sketch of the weir overflow

The discharge equation of the broad-crested weir can be written as

$Q=C_{d} b\left(2 g H_{0}^{3}\right)^{1 / 2}$

where $Q$ is the discharge, $C_{d}$ is the discharge coefficient, $b$ is the channel width, $g$ is the gravitational acceleration. The approach energy head can be calculated by:

$H_{0}=h_{0}+Q^{2} /\left(2 g b^{2}\left(h_{0}+w\right)^{2}\right)$

$C_{d}$ was defined by Fritz and Hager [2] as follow:

$C_{d}=0.43+0.06 \sin (\pi(\varepsilon-0.55))$

They indicated that the discharge coefficient $C_{d}$ is a function of relative crest length $\varepsilon=H_{0} /\left(H_{0}+L_{w}\right)$ with $0<\varepsilon<1$.

\section{EXPERIMENTAL SET-UP AND METHODS}

In this study the effect of upstream and downstream slopes on the broad-crested weir discharge was investigated experimentally. Four different slopes $(0.5 \mathrm{H}: 1 \mathrm{~V}, 1 \mathrm{H}: 1 \mathrm{~V}, 2 \mathrm{H}: 1 \mathrm{~V}, 3 \mathrm{H}: 1 \mathrm{~V})$ and two different weir lengths were tested during the experiments. The upstream and downstream slopes were the same for each experiment. The height of the weir was $7.5 \mathrm{~cm}$. The experiments were carried out in a flume 8 
$\mathrm{m}$ long, $15 \mathrm{~cm}$ wide and $40 \mathrm{~cm}$ high which was built in the Hydraulics Laboratory of Civil Engineering Department in Dokuz Eylul University. The side walls of the flume were built from plexy-glass material. The discharge values were arranged with a spherical valve and the flow rate was measured by means of a calibrated $90^{\circ} \mathrm{V}$-notch weir located at the downstream part of the flume. The flow depth was monitored by the ultrasonic level sensors (ULS) with a precision of $\pm 0.1 \mathrm{~mm}$. The ULS is an ultrasonic laboratory water level measuring system for the flume. It has four independent channels which allow to measure water levels from four different points simultaneously. The superior resolution of up to 180 microns and the repetition rate of up to $50 \mathrm{~Hz}$ so sensors enable users to detect smallest and fastest changes of levels. The sketch of the experimental set up is given in Figure 2.

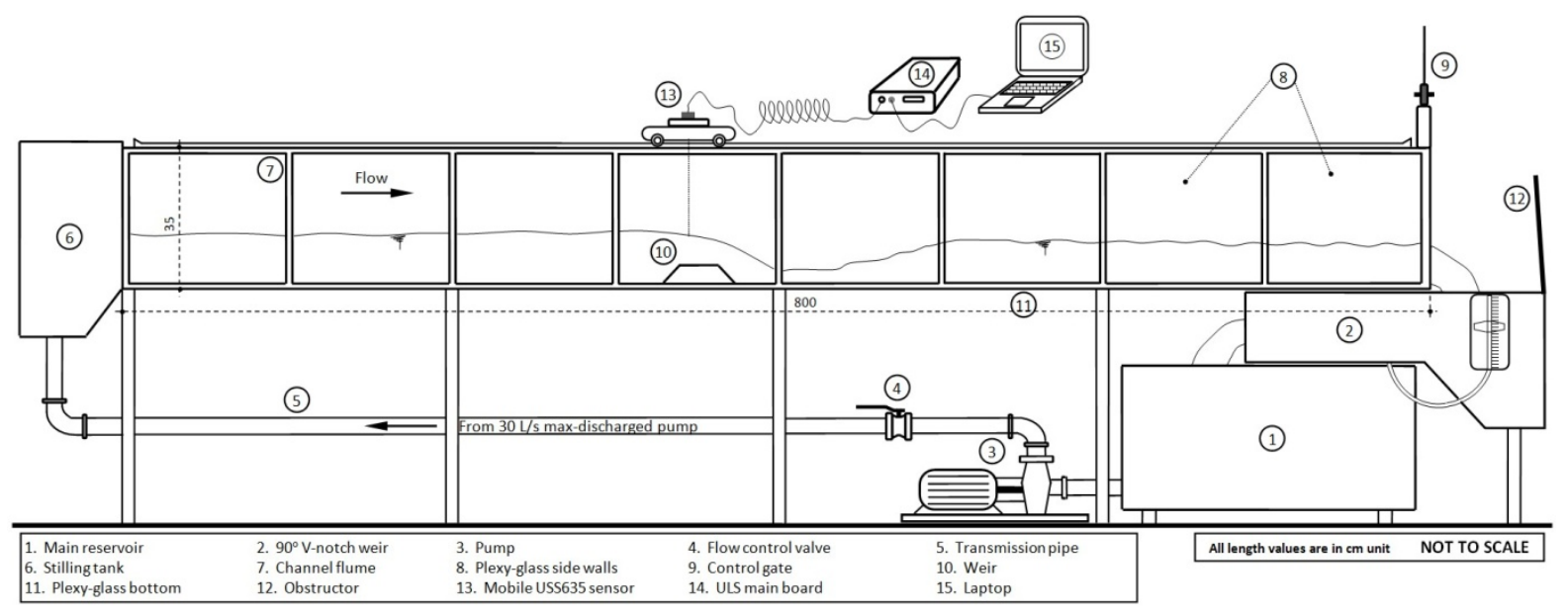

Figure 2. The sketch of the experimental set-up

\section{EXPERIMENTAL RESULTS}

The characteristics of the experiments are given in Table 1. Discharge coefficient $\left(C_{d}\right)$ values were calculated from experimental data by using Equation 1. The range of the discharge value was limited to $1258-3177 \mathrm{~cm}^{3} / \mathrm{s}$ due to the capacity of the pump used for experiments.

Table 1. The characteristics of the experiments

\begin{tabular}{ccccccccccc}
\hline $\begin{array}{c}\text { Experiment } \\
\text { Number }\end{array}$ & $\begin{array}{c}\text { Upstream and } \\
\text { Downstream } \\
\text { Slopes }\end{array}$ & $\begin{array}{c}L_{w} \\
(\mathrm{~cm})\end{array}$ & $\begin{array}{c}Q \\
\left(\mathrm{~cm}^{3} / \mathrm{s}\right)\end{array}$ & $\begin{array}{c}h_{0} \\
(\mathrm{~cm})\end{array}$ & $\begin{array}{c}H_{0} \\
(\mathrm{~cm})\end{array}$ & $F r$ & $\begin{array}{c}R e \\
\left(10^{4}\right)\end{array}$ & $\begin{array}{c}h_{t} \\
(\mathrm{~cm})\end{array}$ & $C_{d}$ & $\begin{array}{c}\text { Average } \\
C_{d}\end{array}$ \\
\hline 1 & $0.5 \mathrm{H}: 1 \mathrm{~V}$ & 10 & 3177 & 5.00 & 5.15 & 0.15 & 27 & 6.95 & 0.41 & \\
2 & $0.5 \mathrm{H}: 1 \mathrm{~V}$ & 10 & 2007 & 3.80 & 3.87 & 0.11 & 18 & 5.65 & 0.40 & 0.39 \\
3 & $0.5 \mathrm{H}: 1 \mathrm{~V}$ & 10 & 1258 & 3.00 & 3.03 & 0.08 & 12 & 4.95 & 0.36 & \\
\hline 4 & $1 \mathrm{H}: 1 \mathrm{~V}$ & 10 & 3177 & 4.60 & 4.76 & 0.16 & 27 & 6.95 & 0.46 & \\
5 & $1 \mathrm{H}: 1 \mathrm{~V}$ & 10 & 2007 & 3.70 & 3.77 & 0.11 & 18 & 5.30 & 0.41 & 0.40 \\
6 & $1 \mathrm{H}: 1 \mathrm{~V}$ & 10 & 1258 & 3.10 & 3.13 & 0.08 & 11 & 4.75 & 0.34 & \\
\hline 7 & $2 \mathrm{H}: 1 \mathrm{~V}$ & 10 & 3177 & 4.80 & 4.95 & 0.16 & 27 & 6.90 & 0.43 & \\
8 & $2 \mathrm{H}: 1 \mathrm{~V}$ & 10 & 2007 & 3.50 & 3.57 & 0.12 & 18 & 5.55 & 0.47 & 0.45 \\
9 & $2 \mathrm{H}: 1 \mathrm{~V}$ & 10 & 1258 & 2.50 & 2.54 & 0.08 & 12 & 4.65 & 0.45 & \\
\hline 10 & $3 \mathrm{H}: 1 \mathrm{~V}$ & 10 & 3177 & 4.60 & 4.76 & 0.16 & 27 & 6.95 & 0.46 & \\
11 & $3 \mathrm{H}: 1 \mathrm{~V}$ & 10 & 2007 & 3.10 & 3.18 & 0.12 & 18 & 5.35 & 0.53 & 0.53 \\
12 & $3 \mathrm{H}: 1 \mathrm{~V}$ & 10 & 1258 & 2.10 & 2.14 & 0.09 & 12 & 4.45 & 0.60 & \\
\hline 13 & $0.5 \mathrm{H}: 1 \mathrm{~V}$ & 15 & 3177 & 5.40 & 5.54 & 0.15 & 27 & 6.85 & 0.37 & \\
14 & $0.5 \mathrm{H}: 1 \mathrm{~V}$ & 15 & 2007 & 4.60 & 4.66 & 0.10 & 17 & 5.65 & 0.31 & 0.34 \\
15 & $0.5 \mathrm{H}: 1 \mathrm{~V}$ & 15 & 1258 & 3.10 & 3.13 & 0.08 & 11 & 4.55 & 0.34 & \\
\hline
\end{tabular}


Özgenç Aksoy and Doğan / Anadolu Univ. J. of Sci. and Technology - A-Appl. Sci. and Eng. 17 (2) - 2016

\begin{tabular}{lllllllllll}
\hline 16 & $1 \mathrm{H}: 1 \mathrm{~V}$ & 15 & 3177 & 4.75 & 4.90 & 0.16 & 27 & 6.90 & 0.44 & \\
17 & $1 \mathrm{H}: 1 \mathrm{~V}$ & 15 & 2007 & 3.90 & 3.98 & 0.11 & 18 & 6.30 & 0.38 & 0.38 \\
18 & $1 \mathrm{H}: 1 \mathrm{~V}$ & 15 & 1258 & 3.20 & 3.24 & 0.08 & 11 & 5.75 & 0.33 & \\
\hline 19 & $2 \mathrm{H}: 1 \mathrm{~V}$ & 15 & 3177 & 5.15 & 5.29 & 0.15 & 27 & 6.65 & 0.39 & \\
20 & $2 \mathrm{H}: 1 \mathrm{~V}$ & 15 & 2007 & 3.70 & 3.77 & 0.11 & 18 & 5.45 & 0.41 & 0.41 \\
21 & $2 \mathrm{H}: 1 \mathrm{~V}$ & 15 & 1258 & 2.70 & 2.73 & 0.08 & 12 & 4.55 & 0.42 & \\
\hline 22 & $3 \mathrm{H}: 1 \mathrm{~V}$ & 15 & 3177 & 4.90 & 5.03 & 0.15 & 27 & 6.75 & 0.42 & \\
23 & $3 \mathrm{H}: 1 \mathrm{~V}$ & 15 & 2007 & 3.45 & 3.52 & 0.12 & 18 & 5.45 & 0.46 & 0.45 \\
24 & $3 \mathrm{H}: 1 \mathrm{~V}$ & 15 & 1258 & 2.55 & 2.58 & 0.08 & 12 & 4.65 & 0.46 & \\
\hline
\end{tabular}

According to computed $C_{d}$ values, it is revealed that they are reduced by increasing the weir length since the approach overflow energy heads $\left(H_{0}\right)$ have bigger values in the case of long weir crest length.

The water surface profiles which were observed during the experiments are given in Figure 3. The flow accelerates and falls along the downstream face of the weir. The critical depth is occurred on the weir crest and is close to the downstream end of the crest. In all cases hydraulic jump is located near the downstream toe of the weir and its length increases with the approach over flow energy head $\left(H_{0}\right)$.

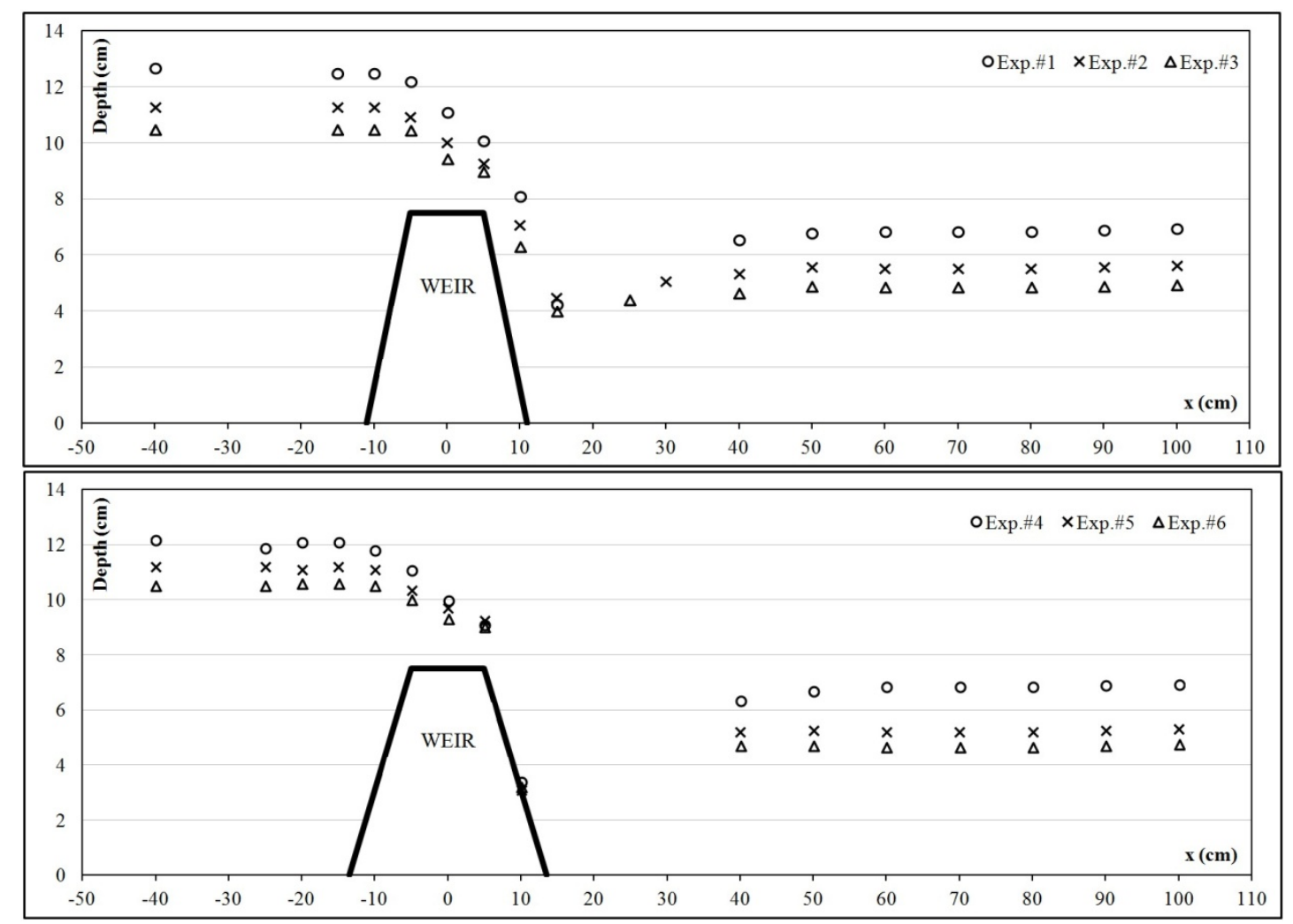

Figure 3. The water surface profiles observed during the experiments 
Özgenç Aksoy and Doğan / Anadolu Univ. J. of Sci. and Technology-A-Appl. Sci. and Eng. 17 (2) - 2016
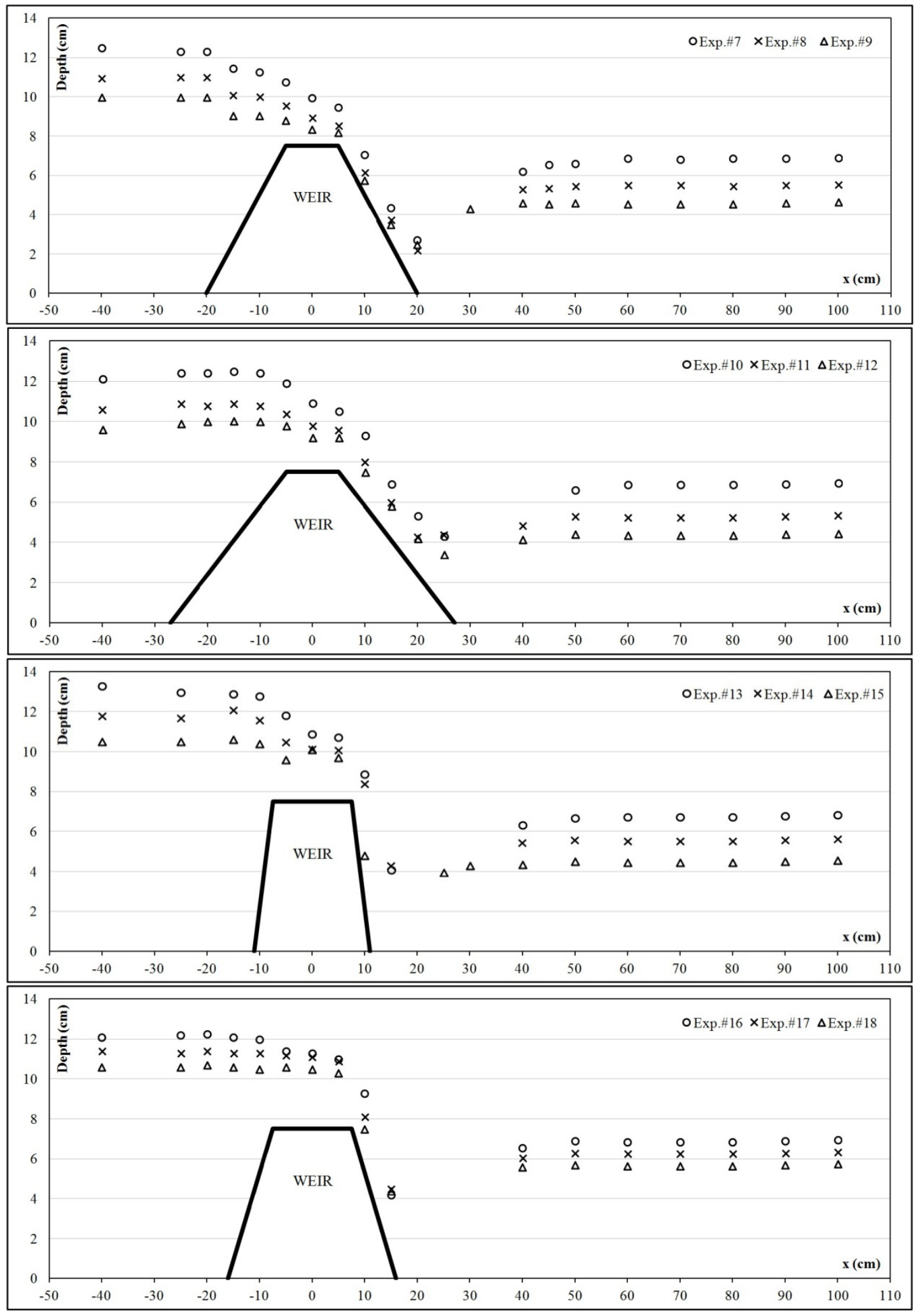

Figure 3. (Continued) The water surface profiles observed during the experiments 

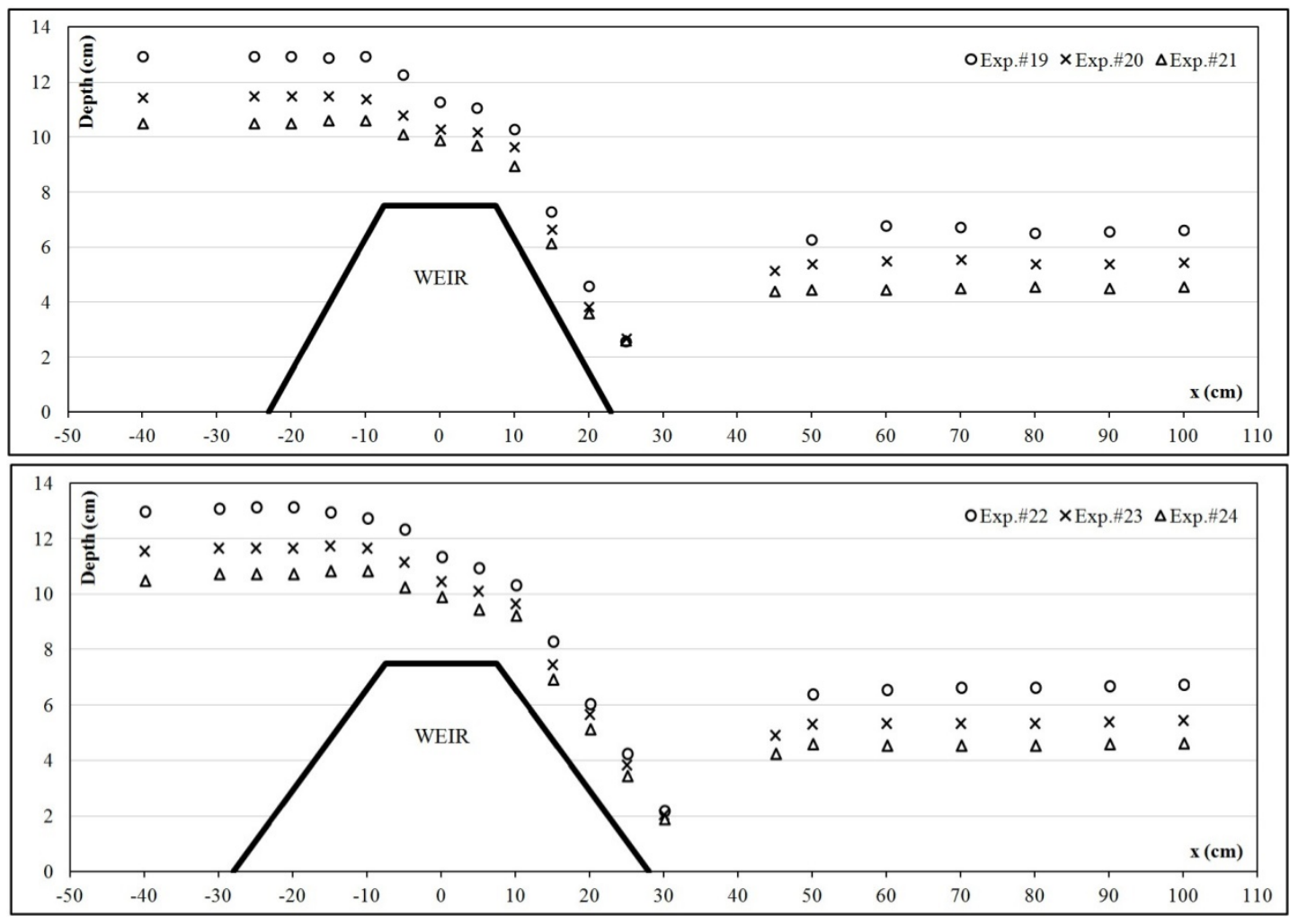

Figure 3. (Continued) The water surface profiles observed during the experiments

Experimental results as shown in Figure 3 indicate that the overflow depth is influenced by the weir crest length. A significant improvement of the discharge efficiency is revealed with decreasing the weir crest length.

The bigger discharge coefficient values were obtained by using the experimental data related weir which has smaller crest length. The variation of $C_{d}$ versus $\theta$ is shown in Figure 4 for two different crest lengths. It is clearly seen that $C_{d}$ decrease by increasing the approach angle. This result is also compatible with the results of the relevant studies in the available literature (such as Goodarzi et al.,[6]).

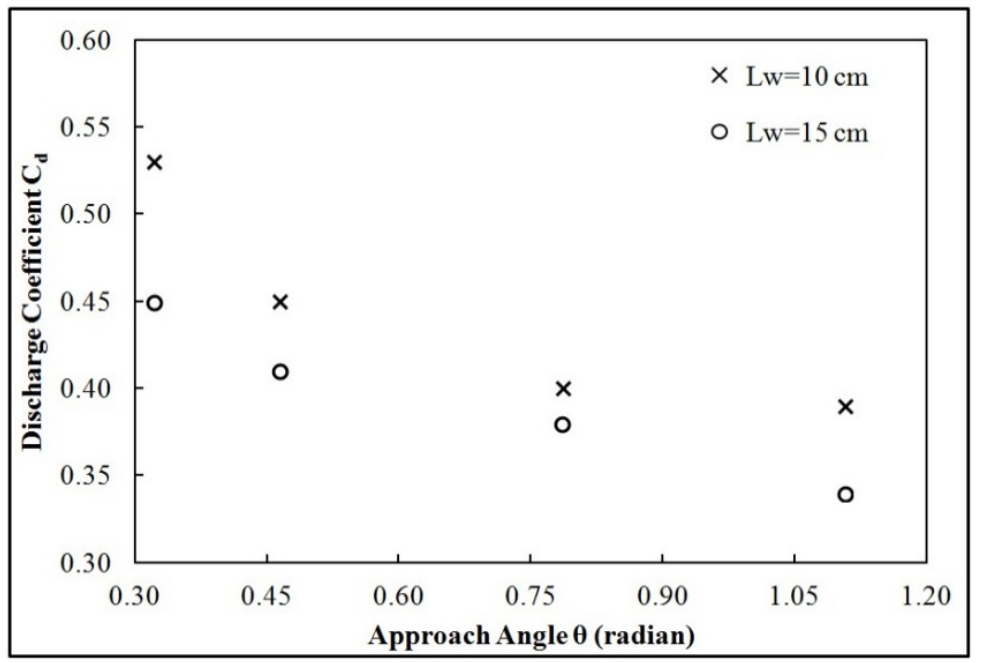

Figure 4. The variation of $C_{d}$ versus $\theta$ 
The performed experiments indicate that discharge coefficient is not only a function of crest length but also a function of approach angle. Thus a discharge coefficient equation is proposed involved approach angle based on the Equation 3 as follow:

$$
C_{d}=[0.43+0.06 \sin (\pi(\varepsilon-0.55))]^{\theta^{1 / 5}}
$$

In this equation the unit of the approach angle $(\theta)$ is radian. Figure 5 shows the calculated discharge coefficient by proposed equation and obtained from experimental data. The figure indicates a good agreement between the calculated and obtained values of discharge coefficient.

The correlation coefficient $(r)$ and the scatter index $(S I)$ are also calculated for the regression equation and the results are given in Figure 5. In this Figure, the scatter index is the ratio between the root mean square errors and experimental averages. The correlation coefficient $(r)$ is calculated as $r=0.87$ which means there is a linear relation between calculated and experimental $C_{d}$ values. The computed scatter index value is $S I=6.95 \%$ which is a quite small value and this value demonstrates the reliability of the proposed equation.

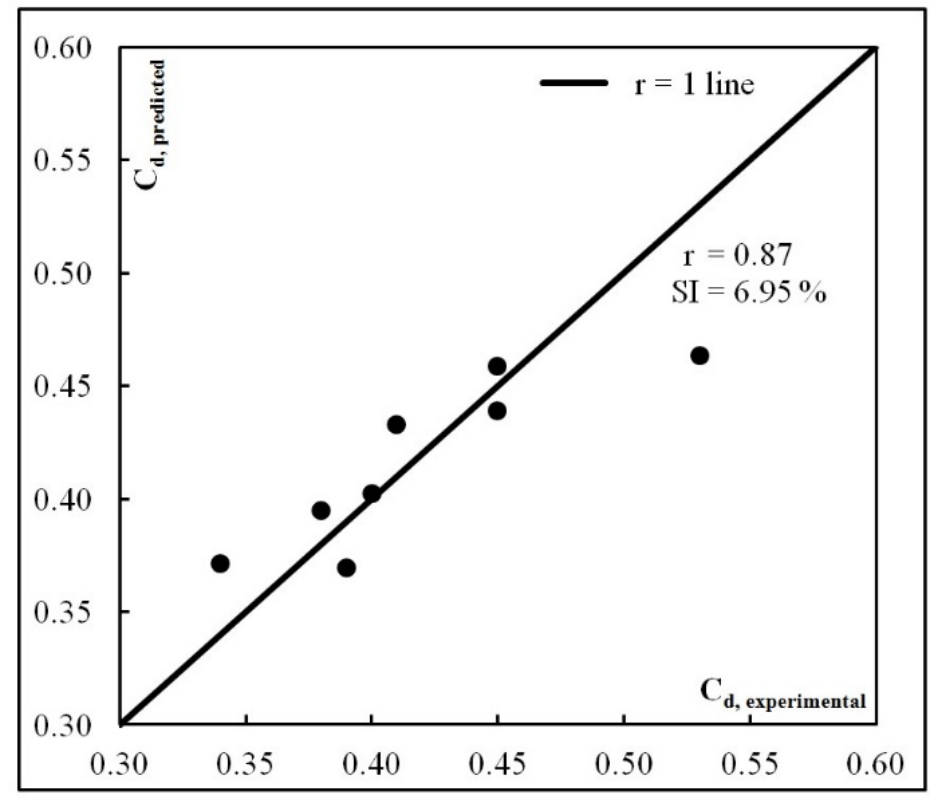

Figure 5. Comparison of calculated and predicted discharge coefficient

\section{CONCLUSION}

In this study, the effect of the approach angle on the discharge efficiency of the broad crested weirs was investigated experimentally. A series of tests were performed in the flume which is available in the Hydraulic Laboratory of Dokuz Eylul University. The test flume has a length of $8 \mathrm{~m}$ and width of $0.15 \mathrm{~m}$. Four different slopes, two different crest lengths and three different flow rates were used during the experiments. Moreover, a widespread literature review was carried out to examine the experimental results in the light of available literature on broad-crested weirs.

The effect of the upstream slope for the broad-crested weirs on the discharge coefficient was presented in Goodarzi et al. [6] and Badr and Mowla [11] studies by the help of correction factor $C_{r}$. However, in the study of Sargison and Percy [5] the effect of the weir slope was considered by attaching a new parameter to Fritz and Hager [2]'s equation. Similarly, in this paper a new empirical relation was 
Özgenç Aksoy and Doğan / Anadolu Univ. J. of Sci. and Technology - A-Appl. Sci. and Eng. 17 (2) - 2016

presented to estimate the discharge coefficient over sloped-face broad-crested weirs by adding the angle of slope parameter to Fritz and Hager [2]'s equation in exponential form.

By analyzing the experimental results the following concluding remarks can be drawn:

1. It is revealed that measured approach flow depths for the short-crested weirs are smaller than those measured for the long-crested weirs.

2. The experimental results indicated that the discharge efficiency increased with the decreasing weir crest length.

3. The results also indicated that the greater the approach angle value, the smaller the discharge coefficient.

4. A new empirical equation was proposed to predict the discharge coefficient, involving the approach angle.

\section{REFERENCES}

[1] Hager WH, Schwalt M. Broad-Crested Weir. Journal of Irrigation and Drainage Engineering 1994; 120(1): 13-26.

[2] Fritz HM, Hager WH. Hydraulics of Embankment Weirs. Journal of Hydraulic Engineering 1998; 124(9): 963-971.

[3] Farhoudi J, Alami S. Slope Effect on Discharge Efficiency in Rectangular Broad-crested Weir with Sloped Upstream Face. International Journal of Civil Engineering 2005; 3(1): 58-65.

[4] Gogus M, Defne Z., Ozkandemir V. Broad-Crested Weirs with Rectangular Compound Cross Sections" Journal of Irrigation and Drainage Engineering 2006; 132(3): 272-280.

[5] Sargison JE, Percy A. Hydraulics of Broad-Crested Weirs with Varying Side Slopes. Journal of Irrigation and Drainage Engineering 2009; 135(1): 115-118.

[6] Goodarzi E, Farhoudi J, Shokri N. Flow Characteristics of Rectangular Broad-Crested Weirs with Sloped Upstream Face. Journal of Hydrology and Hydromechanics 2012; 60(2): 87-100.

[7] Parilkova J, Riha J, Zachoval Z. The Influence of Roughness on the Discharge Coefficient of a Broad-Crested Weir. Journal of Hydrology and Hydromechanics 2012; 60(2): 101-104.

[8] Jalil SA, Ibrahim SS, Jafer RA. Surface Roughness Effects on Discharge Coeffficint of Broadcrested Weir. Research Journal of Applied Sciences, Engineering and Technology 2014; 7(24): $5227-$ 5233.

[9] Zachoval Z., Kneblova M, Rousar L, Rumann J, Sulc J. Discharge Coefficient of a Rectangular Sharp-Edged Broad-Crested Weir. Journal of Hydrology and Hydromechanics 2014; 62(2): 87-100.

[10] Madadi MR., Dalir AH, Farsadizadeh D. Investigation of Flow Characteristics above Trapezoidal Broad-Crested Weirs. Flow Measurement and Instrumentation 2014; 38: 139-148.

[11] Badr K, Mowla D. Development of Rectangular Broad-Crested Weirs for Flow Characteristics and Discharge Measurement. KSCE Journal of Civil Engineering 2015; 19(1): 136-141. 